\title{
Asthma, airways responsiveness and air pollution in two contrasting districts of northern England
}

\author{
G Devereux, T Ayatollahi, R Ward, C Bromly, S J Bourke, S C Stenton, D J Hendrick
}

\begin{abstract}
Background - To assess the possible magnitude of differences between normal populations an epidemiological investigation of asthma was conducted in two strongly contrasting districts of northern England - rural West Cumbria on the west coast and urban Newcastle upon Tyne on the east coast.
\end{abstract}

Methods - A cross sectional survey of randomly identified men aged $20-44$ years was conducted in two phases: phase 1, a postal survey of respiratory symptoms and asthma medication in $\mathbf{3 0 0 0}$ men from each district; and phase 2, a clinical assessment of $\mathbf{3 0 0}$ men from each district comprising investigator administered questionnaires, skin prick tests, spirometry, and methacholine challenge tests.

Results - The phase 1 (but not phase 2) study showed a small excess of "ever wheezed" in Newcastle (44\% versus $40 \%$ ), but neither phase showed differences between the two districts for recent wheeze or for other symptoms characteristic of asthma. There were also no differences with regard to diagnosed asthma, current asthma medication, spirometric parameters, or airways responsiveness. The prevalence of quantifiable airways responsiveness $\left(\mathrm{PD}_{20} \leqslant 6400 \mu \mathrm{g}\right)$ was $27.7 \%$ in West Cumbria and $28.2 \%$ in Newcastle. Regression analyses showed that $\mathbf{P D}_{20}$ was negatively associated with atopy and positively with forced expiratory volume in one second $\left(F E V_{1}\right)$; that an association between $\mathbf{P D}_{20}$ and current smoking could be explained by diminished $F E V_{1}$; and that $\mathbf{P D}_{20}$ was not related to geographical site of residence.

Conclusions - Neither airways responsiveness nor the other parameters of diagnostic relevance to asthma varied much between the two study populations, despite the apparent environmental differences. The most obvious of these were the levels of outdoor air pollution attributable to vehicle exhaust emissions, the ambient levels of which were 2-10 fold greater in Newcastle. Our findings consequently shed some doubt over the role of such pollution in perceived recent increases in asthma prevalence. It is possible, however, that an air pollution effect in Newcastle has been balanced by asthmagenic effects of other agents in West Cumbria.

(Thorax 1996;51:169-174)

Keywords: asthma, epidemiology, airways responsiveness, air pollution.

There is concern at present over reported increases in asthma symptoms, diagnosis, medication, sickness absence, hospital admission, and death. ${ }^{1-7}$ These apparent increases in morbidity and mortality have occurred despite advances in the understanding and management of the disease,$^{89}$ and despite diminishing morbidity and mortality from other diseases amenable to effective preventive and therapeutic intervention. ${ }^{10} \mathrm{~A}$ plausible and popular explanation is that the incidence of asthma is increasing, though trends may have been exaggerated by changes in diagnostic fashion. ${ }^{11}$

Migration and twin studies have shown that asthma is largely an acquired disease determined by environmental factors. ${ }^{12-14} \mathrm{~A}$ logical step towards their elucidation is standardised investigation of populations living under different environmental conditions. Although a number of studies in Britain have reported subjective and objective evidence of asthma prevalence, most have been restricted to single populations and few have used identical methods. Comparisons of prevalence between regions have consequently proved to be difficult, and controversy has arisen over the interpretation of geographical differences and recent time trends in the epidemiology of asthma.

The present investigation was devised to see if there were any differences in the prevalence of asthma in normal populations living in two health districts of the Northern Health Region of England. To provide the greatest opportunity for demonstrating differences several subjective and objective measures of asthma prevalence were included and two strongly contrasting districts - rural West Cumbria on the west coast and urban Newcastle upon Tyne on the east coast - were chosen. These geographical differences confer mild differences in temperature, rainfall, and prevailing wind, considerable differences in the levels of outdoor ambient air pollution from vehicle exhausts and, possibly, qualitative and quantitative differences in airborne aeroallergens. To avoid any confounding effects from sex we chose to study only men. 


\section{Methods}

Geographical data were obtained from the Ordnance Survey and meteorological data from the Newcastle Meteorological Centre. Pollution data from West Cumbrian town centres were provided by Allerdale and Copeland borough councils. Pollution data from a central site in Newcastle were obtained from the Department of the Environment. ${ }^{15}$

PHASE 1

Phase 1 was a 1992 postal survey of 3000 men aged 20-44 years in each district randomly chosen from Family Health Service Authority (FHSA) registers (a 15\% sample of those eligible in West Cumbria and 5\% in Newcastle). It was anticipated that symptom prevalences would range between $5 \%$ and $40 \%$, and that at least 1500 men in each district would respond. In such circumstances, phase 1 would have $80 \%$ power to detect a $5 \%$ difference in symptom prevalence at the $5 \%$ level of significance. A questionnaire based on the European Community Respiratory Health Survey (ECRHS) screening questionnaire was mailed up to a maximum of three times. ${ }^{16}$ It sought demographic details and symptoms/treatment relevant to asthma. Evidence for response bias was sought by comparing replies to the three individual mailings. To clarify reasons for nonresponse, the names of occupants actually residing at the addresses of a random $10 \%$ sample of non-responders were determined by inspection of electoral rolls.

PHASE 2

Phase 2 was a detailed clinical assessment of a sample of phase 1 responders from each district. With an anticipated $30 \%$ prevalence of quantifiable airways responsiveness, ${ }^{17}$ approximately 300 subjects would be required in each district to provide an $80 \%$ chance of detecting a $10 \%$ difference at a $5 \%$ level of significance. Randomly chosen responders to phase 1 were recruited by mail to participate in phase 2 until the required numbers were obtained. Phase 2 took place concurrently in both districts between October 1992 and March 1993, and comprised an interviewer administered questionnaire, skin prick tests using six common allergens, spirometric tests, and a methacholine challenge test. To clarify phase 2 response bias, responses to the phase 1 postal questionnaire were compared between phase 2 participants and phase 1 responders not invited to participate in phase 2 . Socioeconomic and smoking characteristics of phase 2 participants were compared with national statistics. ${ }^{18} 19$ Ethical approval was obtained from the West Cumbrian and the Newcastle ethics committees and all participants gave written informed consent.

The study design followed that of an earlier investigation of asthma in shipyard workers. ${ }^{17}$ Details of the methods used for spirometric tests, skin prick tests, and methacholine challenge tests have been published previously. ${ }^{170-22}$ Nebulised methacholine was administered in doubling cumulative doses over the range $3 \cdot 125-6400 \mu \mathrm{g}$ and airways responsiveness was expressed as a conventional $\mathrm{PD}_{20}$. Using this methodology, $\mathrm{PD}_{20}$ values of $<200 \mu \mathrm{g}$ are almost always associated with active asthma, 200-1000 $\mu \mathrm{g}$ are sometimes associated with active asthma, and $>1000 \mu \mathrm{g}$ are very rarely associated with active asthma. ${ }^{23}$

\section{DATA ANALYSIS}

Statistical analyses utilised the STATA Release 3 statistical package (Computing Resource Center, Santa Monica, USA). Adjustment for phase 1 response bias used the method proposed by Drane which assumes linearly decreasing prevalences for those responding to the first, second, and third phase 1 mailings. ${ }^{24}$ A linear regression model was fitted to the observed prevalences and the prevalences of non-responders were obtained by extrapolation, enabling adjustment of the observed prevalences for non-response. Phase 2 response bias was quantified by logistic regression of phase 2 participation against age, district of residence, and phase 1 questionnaire responses.

Logistic regression analyses of phase 2 questionnaire responses related the proportions of subjects with a positive response to a given question to age, district of residence, smoking history, social class, and atopic status. Regression analyses of airways responsiveness data related $\mathrm{PD}_{20}$ to district of residence, age, smoking habit, atopic status, and baseline ventilatory function as expressed by $\mathrm{FEV}_{1}$. Regression of airways responsiveness is complicated by "right censoring" of $\mathrm{PD}_{20}$ values at the maximum quantifiable level $(6400 \mu \mathrm{g}$ methacholine using our protocol). ${ }^{25}$ To utilise all the $\mathrm{PD}_{20}$ data we used two multiple regression techniques. Logistic regression assessed the probability of obtaining (i) a $\mathrm{PD}_{20}$ of $\leqslant 6400 \mu \mathrm{g}$ (that is, a positive methacholine test), and (ii) $\mathrm{PD}_{20} \leqslant 1000 \mu \mathrm{g}$ (that is, airways responsiveness with which asthmatic symptoms are usually associated). Regression analysis for censored data used the log transformed values for $\mathrm{PD}_{20}$ with values of $>6400 \mu \mathrm{g}$ being identified as "right censored". ${ }^{26}$

\section{Results}

The West Cumbrian and Newcastle health districts comprise, respectively, approximately $1200 \mathrm{~km}^{2}$ adjacent to the west coast and $112 \mathrm{~km}^{2}$ adjacent to the east coast of northern England. The respective populations are 138000 and 300000 . The West Cumbrian district is rural, two thirds being within the Lake District national park. Small towns are scattered down the extensive western coastal plain and the local economy depends on light industry, farming, tourism, and nuclear reprocessing. Traffic is spread over a large area with 237000 vehicles registered in the administrative county of Cumbria (an average of $35 / \mathrm{km}^{2}$ ). There is some concentration in the towns of Whitehaven and Workington. The city of Newcastle upon Tyne, and the Tyneside conurbation of which it is a part, is dependent economically on the service industries and light 
Table 1 Demographic data for West Cumbria and Newcastle

\begin{tabular}{lll}
\hline & West Cumbria & Newcastle \\
\hline Geographical location & West coast & East coast \\
Mean mid-day temperature & $12 \cdot 4^{\circ} \mathrm{C}$ & $12 \cdot 0^{\circ} \mathrm{C}$ \\
Annual rainfall (mm) & 834 & 618 \\
Predominant wind direction & From the sea & From the land \\
Locality & Dominantly rural & Urban \\
Annual average level of air pollutant* & & 28 \\
Nitrogen dioxide $(\mathrm{ppb})$ & 10 & 7 \\
Sulphur dioxide $(\mathrm{ppb})$ & 6 & 29 \\
Particulate $\mathrm{PM}_{10}\left(\mu \mathrm{g} / \mathrm{m}^{3}\right)$ & 7 & \\
\hline
\end{tabular}

* West Cumbria, mean of 4-6 sites including Whitehaven and Workington. Newcastle, single site.

Table 2 Results of phase 1 postal questionnaires

\begin{tabular}{lcc}
\hline & $\begin{array}{l}\text { West Cumbria } \\
(n=1802)\end{array}$ & $\begin{array}{l}\text { Newcastle } \\
(n=1368)\end{array}$ \\
\hline $\begin{array}{l}\text { Ever wheezed } \\
\text { Woken wheezing, last year }\end{array}$ & $39 \cdot 9 \%$ & $44 \cdot 1 \% *$ \\
Woken with chest tightness, & $8 \cdot 1 \%$ & $8 \cdot 8 \%$ \\
$\quad \begin{array}{l}\text { last year } \\
\text { Woken by shortness of breath, }\end{array}$ & $17 \cdot 0 \%$ & $18 \cdot 8 \%$ \\
$\quad \begin{array}{l}\text { last year } \\
\text { Woken by coughing, last year }\end{array}$ & $8 \cdot 6 \%$ & $9 \cdot 8 \%$ \\
$\begin{array}{l}\text { Currently taking asthma } \\
\text { medication }\end{array}$ & $7 \cdot 3 \%$ & $24 \cdot 7 \%$ \\
\hline $\mathrm{*}=0.02\left(\chi^{2}\right.$ test). & & $6 \cdot 9 \%$ \\
\hline
\end{tabular}

Table 3 Socioeconomic characteristics of phase 2 subjects

\begin{tabular}{|c|c|c|c|c|}
\hline \multirow[t]{2}{*}{ Social class } & \multicolumn{2}{|c|}{ West Cumbrian men } & \multicolumn{2}{|c|}{ Newcastle men } \\
\hline & Phase 2 & 1991 census & Phase 2 & 1991 census \\
\hline $\begin{array}{l}\text { I } \\
\text { II } \\
\text { III } \\
\text { IV } \\
\text { V }\end{array}$ & $\begin{array}{r}11 \cdot 4 \% \\
17 \cdot 1 \% \\
53 \cdot 0 \% \\
12 \cdot 8 \% \\
5 \cdot 7 \%\end{array}$ & $\begin{array}{r}5 \cdot 4 \% \\
21 \cdot 9 \% \\
44 \cdot 7 \% \\
20 \cdot 3 \% \\
7 \cdot 7 \%\end{array}$ & $\begin{array}{r}8 \cdot 7 \% \\
26 \cdot 1 \% \\
42 \cdot 3 \% \\
12 \cdot 9 \% \\
10 \cdot 0 \%\end{array}$ & $\begin{array}{r}8 \cdot 8 \% \\
23 \cdot 3 \% \\
45 \cdot 1 \% \\
15 \cdot 8 \% \\
7 \cdot 0 \%\end{array}$ \\
\hline
\end{tabular}

industry. It attracts a heavy burden of traffic into a small area and at present 353000 vehicles are registered in the administrative county of Tyne and Wear (an average of $650 / \mathrm{km}^{2}$ ). Data from the Enhanced Urban Monitoring Initiative suggest that in 1992-3 Newcastle was one of the most polluted of British cities with respect to ambient and peak levels of nitrogen dioxide. ${ }^{15}$ Environmental data are summarised in table 1.

PHASE 1

There were 1802 completed questionnaires from West Cumbria and 1368 from Newcastle - apparent response rates of $59 \%$ and $45 \%$, respectively. Of the $10 \%$ samples of nonresponders, only 31 of $112(28 \%)$ in West Cumbria and 26 of $158(16 \%)$ in Newcastle appeared to be living at the addresses to which

Table 4 Results of phase 2 questionnaire

\begin{tabular}{|c|c|c|c|}
\hline Symptom & $\begin{array}{l}\text { West Cumbria } \\
(n=298)\end{array}$ & $\begin{array}{l}\text { Newcastle } \\
(n=310)\end{array}$ & $p$ \\
\hline Ever wheezed & $45 \cdot 3 \%$ & $43 \cdot 2 \%$ & NS \\
\hline Wheezed in last year & $32 \cdot 1 \%$ & $28 \cdot 5 \%$ & NS \\
\hline Woken wheezing, last year & $13 \cdot 5 \%$ & $11 \cdot 3 \%$ & NS \\
\hline Woken with chest tightness, last year & $12 \cdot 0 \%$ & $11 \cdot 1 \%$ & NS \\
\hline Woken by shortness of breath, last year & $7 \cdot 4 \%$ & $7 \cdot 2 \%$ & NS \\
\hline Woken by coughing, last year & $19.9 \%$ & $23.6 \%$ & NS \\
\hline Ever diagnosed asthmatic & $13.0 \%$ & $11.0 \%$ & NS \\
\hline Medications for asthma, last year & $11 \cdot 5 \%$ & $9 \cdot 1 \%$ & NS \\
\hline Usually cough on winter mornings & $13.9 \%$ & $24.5 \%$ & $<0.01$ \\
\hline Usually produce phlegm on winter mornings & $14.0 \%$ & $26 \cdot 6 \%$ & $<0.01$ \\
\hline Usually cough during rest of day in winter & $8.6 \%$ & $16.5 \%$ & $<0.001$ \\
\hline Usually produce phlegm rest of day in winter & $8 \cdot 2 \%$ & $21 \cdot 4 \%$ & $<0.001$ \\
\hline
\end{tabular}

Percentages are given because a few subjects responded "don't know" to some questions. the questionnaires were sent. We consequently estimate that 2134 questionnaires were delivered appropriately in West Cumbria and 1637 in Newcastle, implying that the true response rates were $84 \%$ (95\% CI $81 \%$ to $89 \%)$ in West Cumbria and $84 \%(79 \%$ to $89 \%)$ in Newcastle. The mean (SD) age of West Cumbrian respondents was $32 \cdot 3(6 \cdot 8)$ years and in Newcastle was $32.3(7 \cdot 0)$ years. Table 2 demonstrates that the only significant difference between the two districts was in the prevalence of those who had "ever wheezed", which was higher in Newcastle.

Inspection of symptom prevalences for the three mailings indicated that those from the first mailing were generally the highest and those from the second mailing the lowest. Extrapolation of these observed prevalences to assess response bias suggested that the true prevalences were $92-99 \%$ (mean $97 \%$ ) of those recorded. Response bias was very similar in both districts.

PHASE 2

Recruitment to phase 2 from West Cumbria and Newcastle ceased when 298 and 310 men, respectively, had participated from those responding to the phase 1 study (response rates of $42 \%$ and $41 \%$ ). The mean ages in West Cumbria and Newcastle were $34 \cdot 1$ (95\% CI $33 \cdot 3$ to $34 \cdot 8)$ and $33 \cdot 1(32.3$ to 33.9$)$ years which were not significantly different. Socioeconomic profiles (as defined by the Registrar General's classification ${ }^{27}$ ) were broadly similar (table 3), though the West Cumbrian participants were less closely representative of the parent population. ${ }^{18}$

Bias towards phase 2 participation was associated with increasing age (odds ratio 1.03 per year) and the presence of positive responses to the six phase 1 questions. The estimated prevalences of positive responses to each question among those not invited to participate were $71-96 \%$ (mean $80 \%$ ) of those recorded by the phase 2 participants after allowing for the effect of age. There was no significant effect of district of residence and there were no interactions between district of residence and symptoms, indicating that similar response biases operated in the two districts.

\section{Questionnaires}

There were no significant differences between the two districts in the prevalence of symptoms consistent with asthma, diagnosed asthma, and current use of asthma medication (table 4). The subjects from Newcastle had significantly more bronchitic syptoms (regular productive cough) than those from West Cumbria. The prevalence of bronchitic symptoms increased significantly across the social classes I-V, but this was the result of a confounding effect of smoking. Bronchitic symptoms were still more prevalent in Newcastle even after adjustment for age, former smoking, current smoking, and social class. There was no relation, however, between this subjective evidence for chronic 




Cumulative distribution of $P D_{20}$ measurements (with $95 \%$ confidence intervals).

bronchitis and the levels of air pollution measured by separate monitoring stations in either West Cumbria or Newcastle.

Men from West Cumbria were less likely to have ever smoked $(45.3 \%)$ than those from Newcastle $(56.5 \% ; \mathrm{p}=0.01)$, but there was no significant difference in the proportion of current smokers $(24.5 \%$ versus $28 \cdot 1 \%)$, nor in pack year consumption of current smokers $(11 \cdot 4$ versus $12 \cdot 8)$. The overall prevalence of current smoking of $26 \%$ was significantly lower than the 33\% reported for $20-49$ year olds in England and Wales, ${ }^{19}$ suggesting that smokers were reluctant to participate.
Spirometric and skin prick tests

There were no significant differences between the districts in spirometric or prick test reactivity. Mean height was $1.77 \mathrm{~m}$ in both West Cumbria and Newcastle, mean $\mathrm{FEV}_{1}$ was $4 \cdot 201$ ( $101 \%$ predicted) and $4 \cdot 281$ (103\% predicted), respectively, and mean forced vital capacity (FVC) was $5 \cdot 141$ (103\% predicted) and 5.11 (103\% predicted). At least one positive prick test was obtained in $28.2 \%$ of West Cumbrian men and $28.4 \%$ of Newcastle men. Skin prick test reactivity was negatively associated with social class, $37 \cdot 7 \%$ of class I, $34.9 \%$ of class II, $26 \cdot 3 \%$ of class III, $25 \cdot 6 \%$ of class IV, and $15 \cdot 4 \%$ of class $\mathrm{V}$ having at least one positive test.

\section{Airways responsiveness}

In West Cumbria 285 men underwent methacholine tests and in Newcastle 302, the remaining 19 being unsuitable or unwilling. Positive tests $\left(\mathrm{PD}_{20} \leqslant 6400 \mu \mathrm{g}\right)$ were obtained in $27 \cdot 7 \%$ and $28 \cdot 2 \%$, respectively, the corresponding figures for $\mathrm{PD}_{20} \leqslant 1000 \mu \mathrm{g}$ being $17 \cdot 5 \%$ and $15 \cdot 6 \%$. There were no significant differences in the distribution of $\mathrm{PD}_{20}$ values (figure).

\section{REGRESSION ANALYSES}

Logistic regression indicated that the district of residence did not influence the prevalence of wheezing, chest tightness, nocturnal breathlessness, or nocturnal coughing symptoms. The results for wheezing symptoms are detailed in table 5. The symptoms "ever wheezed" and

Table 5 Phase 2: logistic regression analysis, proportion of subjects with wheezing symptoms

\begin{tabular}{llll}
\hline Covariate & \multicolumn{2}{l}{ Odds ratios (95\% confidence interval) } & \\
\cline { 2 - 4 } & Ever wheezed & Wheezed, last year & Woken wheezing, last year \\
\hline West Cumbria vs Newcastle & 1.23 & 1.27 & 1.15 \\
& $(0.86$ to 1.75$)$ & $(0.88$ to 1.85$)$ & $(0.69$ to 1.91$)$ \\
Age (per year) & 0.99 & 1.01 & 1.04 \\
Social class, I-V (per class) & $(0.97$ to 1.03$)$ & $(0.98$ to 1.04$)$ & $(0.99$ to 1.08$)$ \\
Ex-smoker vs never smoker & $1.32^{*}$ & $1.33 *$ & 1.26 \\
Current vs never smoker & $(1.10$ to 1.58$)$ & 1.10 to 1.61$)$ & $(0.98$ to 1.63$)$ \\
Atopy (per positive allergen) & $1.92^{*}$ & $(0.73$ to 1.98$)$ & 0.70 \\
& $(1.23$ to 3.01$)$ & $3.03 \dagger$ & $(0.35$ to 1.39$)$ \\
& $(2.46 \dagger$ to 5.79$)$ & $(1.96$ to 4.69$)$ & 1.05 \\
& $2.53 \dagger$ & $2.05 \dagger$ & 1.58 to 1.91$)$ \\
\end{tabular}

$* \mathrm{p}<0.01 ;+\mathrm{p}<0.001$.

Table 6 Logistic regression $P D_{20} \leqslant 6400 \mu \mathrm{g}$ and $P D_{20} \leqslant 1000 \mu \mathrm{g}$ and regression analysis for censored data, $\log _{10}\left(P D_{20}\right)$

\begin{tabular}{|c|c|c|c|}
\hline \multirow[t]{2}{*}{ Covariate } & \multicolumn{2}{|c|}{$\begin{array}{l}\text { Odds ratio } \\
(95 \% \text { confidence interval) }\end{array}$} & \multirow{2}{*}{$\begin{array}{l}\text { Regression coefficient } \\
\text { (95\% confidence } \\
\text { interval) }\end{array}$} \\
\hline & $P D_{20} \leqslant 6400 \mu g$ & $P D_{20} \leqslant 1000 \mu g$ & \\
\hline West Cumbria vs Newcastle & $\begin{array}{l}1.00 \\
(0.68 \text { to } 1.48)\end{array}$ & $\begin{array}{l}1.22 \\
(0.75 \text { to } 1.98)\end{array}$ & $\begin{array}{l}-0.050 \\
(-0.35 \text { to } 0.249)\end{array}$ \\
\hline Age (per year) & $\begin{array}{l}0.97 \\
(0.94 \text { to } 1.00)\end{array}$ & $\begin{array}{l}0.97 \\
(0.94 \text { to } 1.00)\end{array}$ & $\begin{array}{l}0.019 \\
(-0.005 \text { to } 0.43)\end{array}$ \\
\hline Social class I-V (per class) & $\begin{array}{l}1.07 \\
(0.87 \text { to } 1 \cdot 32)\end{array}$ & $\begin{array}{l}1.21 \\
(0.93 \text { to } 1.56)\end{array}$ & $\begin{array}{l}-0.088 \\
(-0.246 \text { to } 0.07)\end{array}$ \\
\hline Current vs non-current smoking & $\begin{array}{l}1.53 \\
(0.99 \text { to } 2.36)\end{array}$ & $\begin{array}{l}1.40 \\
(0.83 \text { to } 2 \cdot 37)\end{array}$ & $\begin{array}{l}-0.323 \\
(-0.654 \text { to } 0.009)\end{array}$ \\
\hline Atopy (per positive allergen) & $\begin{array}{l}2.31^{*} \\
(1.79 \text { to } 2.99)\end{array}$ & $\begin{array}{l}2.76^{*} \\
(2.08 \text { to } 3 \cdot 67)\end{array}$ & $\begin{array}{l}-0.765^{*} \\
(-0.951 \text { to }-0.578)\end{array}$ \\
\hline Baseline $\mathrm{FEV}_{1}$ (per litre) & $\begin{array}{l}0.49^{*} \\
(0.36 \text { to } 0.66)\end{array}$ & $\begin{array}{l}0.41^{*} \\
(0.28 \text { to } 0.60)\end{array}$ & $\begin{array}{l}0.646^{*} \\
(0.414 \text { to } 0.879)\end{array}$ \\
\hline Constant & & & 1.421 \\
\hline
\end{tabular}

$* \mathrm{p}<0 \cdot 001$. 
"wheezed in last year" were influenced by social class, smoking, and atopy. The more specific symptom of "nocturnal wheeze in the last year" was associated with atopy only.

For airways responsiveness, multiple logistic regression analysis and multiple regression analysis for censored data showed that $\mathrm{PD}_{20}$ was positively associated with baseline $\mathrm{FEV}_{1}$ and negatively with atopic status (table 6 ). There was no hint of an association with district of residence. A highly significant negative association was found between $\mathrm{PD}_{20}$ and current smoking, but adjustment for baseline $\mathrm{FEV}_{1}$ weakened the relationship to borderline significance, indicating that it resulted largely from the confounding influence of $\mathrm{FEV}_{1}$. These findings are consistent with previous studies. ${ }^{28-33}$ Airways responsiveness was not influenced by "former smoking". There were no significant associations between $\log \left(\mathrm{PD}_{20}\right)$ and interactive terms combining age and smoking, age and atopic status, or smoking and atopic status.

\section{Discussion}

We were surprised by the degree of concordance from the various indicators used to assess the prevalence of asthma. These included the symptoms described by the participants themselves, the reported diagnoses (and prescribed medications) of their physicians, and the objective measurements of spirometry and airways responsiveness obtained in the study. Such concordance provides confidence for interpreting the results, particularly as the data were obtained by the same investigators in both districts using the same methods and the same equipment. Although response bias was evident in recruitment of the phase 1 and (particularly) the phase 2 participants, it was similar in both districts and consistent with previous studies. ${ }^{3435}$ We do not think it likely that bias exerted an important influence on the conclusion that there is no important difference between the two districts in the prevalence of asthma.

The absence of such a difference was unexpected because the two districts were chosen for their strongly contrasting environmental characteristics. This implies that the environmental differences were not of much relevance to asthma aetiology, or that relevant factors in one district were balanced by different factors of relevance in the other.

Most prominent among the environmental differences was the contrast between rural and urban settings, and in particular the levels of outdoor air pollution attributable to vehicle exhaust emissions. Although we did not quantify pollutant levels ourselves, contemporary regular monitoring was carried out in both districts for the two pollutants most dependent on vehicle emissions - nitrogen dioxide and small particulates. Both were measured in clear excess in Newcastle compared with West Cumbria, confirming a difference which is intuitively obvious. Current exposures are, of course, less relevant than the exposures that existed when asthma and airways hyperresponsiveness first began in these men, and some of them would not have lived in either district at the relevant time. However, experience with occupational asthma indicates that most affected workers first develop symptoms within one or two years after first exposure, and often within a few months. Furthermore, the mean periods of residence of the participants in West Cumbria and Newcastle were 28 and 25 years, respectively. An important asthmagenic effect attributable to vehicle emissions should consequently have caused an excess prevalence in Newcastle and been readily detectable from the investigation, since marked differences in vehicle use have existed between the two study districts throughout the lifetimes of all the participants.

Our findings consequently suggest that vehicle emissions may not be of major relevance to the aetiology of asthma unless a vehicle emission effect in Newcastle has been balanced by an equal effect from some other factor(s) in West Cumbria. Such a possibility is plausible, though it is not perhaps likely. Of the several other differences between the two districts and the two populations, those associated with climatic, vegetative, socioeconomic, recreational, and occupational variables were of mild or minor degree and hence of doubtful importance unless their effects were all exerted in the same direction. There was, for example, a mild but significant excess of dog keepers among the phase 2 men in West Cumbria, and these subjects were more likely to use rugs in their homes, to use coal or gas fires, and to have double glazing. However, the Newcastle men used gas cookers and gas boilers more commonly and, curiously, kept cats and dogs more commonly in childhood. These variables were not associated with any of the diagnostic parameters of asthma, and their inclusion in the regression analyses did not lead to the emergence of "residential district" as a factor significantly associated with asthma symptoms or airways responsiveness.

Differences in exposure to ozone are less easily dismissed, especially as comprehensive monitoring data were not available to compare the two districts. Ozone generation is greatly enhanced when air pollutants from industrial conurbations are slow to disperse because of atmospheric stagnation (stable high barometric pressure), and when there is excess ultraviolet radiation. The necessary conditions for photochemical interaction are particularly favoured when heavily polluted air drifts slowly to country districts of high altitude in summer, conditions which are relevant in West Cumbria. Within polluted cities themselves ozone levels tend to be lower because the production of nitric oxide readily leads to oxidation reactions with ozone, thereby increasing nitrogen dioxide levels but decreasing the levels of ozone. While these processes may have produced higher cumulative exposures to ozone in West Cumbria than in Newcastle, it should be recognised that exposure peaks occur only sporadically in country districts while excess vehicle emissions occur continuously in urban settings. 
We did not address the question of whether air pollution from vehicle emissions exacerbates asthma in subjects already affected. It is important to recognise the difference. The evidence that air pollution may increase morbidity in established asthma is already quite strong, ${ }^{36-40}$ though doubts remain as to whether particular measured pollutants such as nitrogen dioxide, ozone, sulphur dioxide, volatile organic compounds, or particulates are truly responsible (whether individually, collectively, or through interactions), or whether they act as markers for additional components of polluted outdoor air.

1 Jackson R, Sears MR, Beaglehole R, Rea HH. International trends in asthma mortality: 1970 to 1985 . Chest 1988:94: 914-9.

2 Burney PGJ. Asthma mortality in England and Wales: evidence for a further increase, 1974-84. Lancet 1986;ii:323-6.

3 Anderson HR. Increase in hospital admissions for childhood asthma: trends in referral, severity, and readmissions from 1970 to 1985 in a health region of the United Kingdom. Thorax 1989;44:614-9.

4 Evans R, Mullally DI, Wilson RW, Gergen PJ, Rosenberg HM, Grauman JS, et al. National trends in morbidity and mortality of asthma in the US. Chest 1987;91:65s-74s.

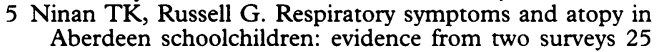
years apart. BMF 1992;304:873-5.

6 Burr ML, Butland BK, King S, Vaughan-Williams E. Changes in asthma prevalence: two surveys 15 years apart. Arch Dis Child 1989;64:1452-6.

7 Fleming DM, Crombie DL. Prevalence of asthma and hayfever in England and Wales. BMF 1987;294:279-83.

Holgate ST. Asthma: past, present and future. Eur Respir $\mathcal{F}$ 1993;6:1507-20.

1993;6:1507-20.
Barnes PJ. A new approach to the treatment of asthma. $N$ Engl f Med 1989;321:1517-26.

10 Charlton JRH, Velez R. Some international comparisons of mortality amenable to medical intervention. $B M \mathcal{F} 1986$; 292:295-301.

11 Britton J. Asthma's changing prevalence. BMF 1992;304: 857-8.

12 Van Niekerk CH, Weinberg EG, Shore SC, De V Heese H, Van Schalkwyk DJ. Prevalence of asthma: a comparative study of urban and rural Xhosa children. Clin Allergy 1979;9:319-24

13 Waite DA, Eyles EF, Tonkin SL, O'Donnell. Asthma prevalence in Tokelauan children in two environments. Clin valence in Tokelauan

14 Edfors-Lubs ML. Allergy in 7000 twin pairs. Acta Allergol 1979;26:249-85.

15 Air pollution in the UK:1992/3. Department of Environment, 1994.

16 European Commission. The European Community Respiratory Health Survey. Medicine and Health, European Commission, Directorate-General XIII, Office for Official Publications, L-2920, Luxembourg.

17 Hendrick DJ, Beach JR, Avery AF, Dennis JH, Bromly CL, Ward RJ, et al. An epidemiological investigation of asthma in apprentice (shipyard) welders. Report to the Medical Research Council and the Health \& Safety Executive, 1994.

18 OPCS. 1991 Census. London: HMSO, 1992.

19 OPCS. General Household Survey. London: HMSO, 1992.
20 Beach JR, Young CL, Avery AJ, Stenton SC, Dennis JH, Walters EH, et al. Measurement of airway responsivenes to methacholine: relative importance of the precision of drug delivery and method of assessing response. Thorax 1993;48:239-43.

21 Hendrick DJ, Fabbri LM, Hughes JM, Banks DE, Barkman HW, Connolly MJ, et al. Modification of the methacholine inhalation test for epidemiologic use. Am Rev Respir Dis 1986;133:600-4.

22 Devereux G, Beach JR, Bromly C, Avery AJ, Ayatollahi SMT, Williams SM, et al. Effect of dietary sodium on airways responsiveness and its importance in the epidemiology of asthma: an evaluation in three areas of demiology of asthma: an evaluation in

23 Stenton SC, Beach JR, Avery AJ, Hendrick DJ. The value of questionnaires and spirometry in asthma surveillance programmes in the workplace. Occupational Med 1993;43: program.

24 Drane JW. Imputing nonresponses to mail-back questionnaires. Am $\mathcal{F}$ Epidemiol 1991;134:908-12.

25 Rijcken B, Schouten JP. Measuring bronchial responsivenes in epidemiology. Eur Respir $\mathcal{F}$ 1993;6:617-8.

26 Amemiya T. Regression analysis when the dependent variable is truncated normal. Econometrica 1973;41:997-1016.

27 OPCS. Registrar General's Socioeconomic Grouping. In Standard Occupational Classification. Vol 3. London: HMSO, 1991.

28 Britton J, Pavord I, Richards K, Knox A, Wisniewski A, Wahedna I, et al. Factors influencing the occurrence of airway hyperreactivity in the general population: the importance of atopy and airway calibre. Eur Respir f 1994; 7:881-7.

29 Trigg CJ, Bennett JB, Tooley M, Sibbald B, D'Souza MF Davies RJ. A general practice based survey of bronchial hyperresponsiveness and its relation to symptoms, sex age, atopy and smoking. Thorax 1990;45:866-72

30 Lim K. Taylor RG, Watson A, Joyce H, Pride NB. Changes in bronchial responsiveness to inhaled histamine over four years in middle aged male smokers and ex-smokers. Thorax 1988;43:599-604.

31 Rijcken B, Schouten JP, Mensinga TT, Weiss ST, De Vries $\mathrm{K}$, Lende RND. Factors associated with bronchial responsiveness to histamine in a population sample of adults. Am Rev Respir Dis 1993;147:1447-53.

32 Burney PGJ, Britton JR, Chinn S, Tattersfield AE, Papacosta AO, Kelson MC, et al. Descriptive epidemiology of bronchial reactivity in an adult population: results from community study. Thorax 1987;42:38-44.

33 Bakke PS, Baste V, Gulsvik. Bronchial responsiveness in a Norwegian community. Am Rev Respir Dis 1991;143: a Norwegia.

34 Bjornsson E, Plaschke P, Norrman E, Janson C, Lundback $\mathrm{B}$, Rosenhall A, et al. Symptoms related to asthma and B, Rosenhall A, et al. Symptoms related to asthma and chronic bronchitis

35 De Marco R, Verlato G, Zanolin E, Bugiani M, Drane JW. Nonresponse bias in EC Respiratory Health Survey in Italy. Eur Respir f 1994;7:2139-45.

36 Dockery DW, Speizer FE, Stram DO, Ware JH, Spengler $\mathrm{D}$, Ferris BG. Effects of inhalable particle on respiratory health of children. Am Rev Respir Dis 1989;139:587-94.

37 Roemer W, Hoek G, Brunekreef B. Effect of ambient winte air pollution on respiratory health of children with chronic respiratory symptoms. Am Rev Respir Dis 1993;147:118 24.

38 Schwartz J, Slater D, Larson TV, Pierson WE, Koenig JQ. Particulate air pollution and hospital emergency room visits for asthma in Seattle. Am Rev Respir Dis 1993;147: 826-31.

39 Pope W, Dockery DW, Spengler JD, Raizenne ME. Respiratory health and $\mathrm{PM}_{10}$ pollution. Am Rev Respir Dis $1991 ; 144: 668-74$

40 Higgins BG, Francis HC, Warburton CJ, Yates C, Fletcher AM, Pickering CAC, et al. The effects of air pollution on peak expiratory flow measurements in subjects with asthma and chronic bronchitis. Thorax 1993;48:417. 